\title{
The improvement of stainless steel properties after pulse plasma processing
}

\section{Anuar Zhukeshov, Asylgul Gabdullina, Assem Amrenova, Svetlana Pak, Jangaly Moldabekov, Marjan Mukhamedryskyzy}

Institute of Experimental and Theoretical Physics, al-Farabi Kazakh National University, Almaty, Kazakhstan

\section{Email address:}

zhukeshov@physics.kz(A. Zhukeshov)

\section{To cite this article:}

Anuar Zhukeshov, Asylgul Gabdullina, Assem Amrenova, Svetlana Pak, Jangaly Moldabekov, Marjan Mukhamedryskyzy. The Improvement of Stainless Steel Properties after Pulse Plasma Processing. International Journal of Materials Science and Applications. Vol. 2, No. 3, 2013, pp. 115-119. doi: 10.11648/j.ijmsa.20130203.18

\begin{abstract}
The results of researches of stainless steel samples surface properties after interaction by pulsed plasma streams are presented. The modification carried out on CPU-30 pulsed plasma accelerator, operated on "continuously filling" mode, by single and multiple times. The structure of material was researched by SEM and XRD methods. The evolution of the grain dimension, in depending on the basic processing parameters is investigated. The physical properties of modified material were significant chance after multiple impacts. The role of new phases and crystal size influence on process are discussed.
\end{abstract}

Keywords: Metal Alloy, Surface, Plasma Processing, Structure, Micro Hardness

\section{Introduction}

In this paper presented the results of studies of stainless steel samples surface properties after modification by pulsed plasma flows, are processed by single and multiple time. The modification carried out on CPU-30 pulsed plasma accelerator, it's operated on continuously filling mode. The working gas air pressure was equal $0.04-0,5$ $\mathrm{mmHg}$ and energy density of plasma was $8-40 \mathrm{~J} / \mathrm{cm} 2$. The changes of materials properties investigated by SEM and XRD methods. The evolution of the grain dimension, as a structural factor of material, in depending on the basic processing parameters was researched. Is shown, the increasing of microhardness of material surface after plasma processing connected with structure changes in steel. The peculiarity of influence of powerful plasma impact on constructional materials is the formation of hardening nitride and carbide phases.

Processing of solid surfaces using pulsed plasma flows is one of the most promising ways to create materials with given properties, including the nanoscale structure materials design. A feature of this method is the high density power impact on the surface of materials, resulting in melting of the surface layer and the cooling rate of 106$10^{8} \mathrm{~K} / \mathrm{s}$ [1-3]. Obviously, the physical parameters of the process leading to the formation of structures of a given size can be achieved only under certain modes of processing. As shown in our works, pulsed plasma accelerator CPU-30 has a power density of $0.5-5 \mathrm{MW} / \mathrm{cm}^{2}$ high enough for surface processing with melting, such as semiconductors, hard and doped metallic materials [4, 5]. Well researched work of the accelerator in pulsed mode, when the working gas is injected into the electrode space before applying a high voltage. In the other case, so called "continuously filling mode", at constant initial gas pressure presented in the chamber, the plasma parameters vary over a wide range. In addition, recently shown that at different gas pressures in the channel of the accelerator can form clots certain form, which may play an important role in the processing of the material.

High heating and cooling speed of the plasma flows promote large temperature gradients on the material, which, in turn, serve as a prerequisite for the activation of chemical reactions on the surface and stimulate the generation and diffusion of radiation-induced defects. In the process of crystallization from the melt in the surface layer of the material may change, leading to the formation of new compounds, the intermediate states are metastable phases. Interest is the study of the mechanism of crystallization in a homogeneous eutectic metal and nonmetal melts, and their relation to structural changes and 
physical characteristics.

In this paper, the generator of pulsed plasma flows is the accelerator with coaxial electrode geometry CPU-30 [6]. CPU-30 generates a plasma flows with velocities (10-100) $10^{3} \mathrm{~m} / \mathrm{s}$ and a high density of the ion kinetic energy from $10 \mathrm{eV}$ to $10^{3} \mathrm{eV}$ with a pulse duration of $\sim 15 \mu \mathrm{s}$. Flux density and efficiency of influence depends on the conditions under which the processing is carried out of the target. In experiment used samples target of nickelchromium alloy with $0,12 \% \mathrm{C}, 18 \% \mathrm{Cr}, 10 \% \mathrm{Ni}$ and low then $1 \% \mathrm{Ti}$ (further $12 \mathrm{X} 18 \mathrm{~N} 10 \mathrm{~T}$ ), whose surface has been treated with a residual air pressure in the working channel of the accelerator. Processing in this mode is characterized by a homogeneous energy distribution of the plasma flow on the surface of the study object. Was selected a wide range of operating pressures $\mathrm{P}=0,04 \div 0,5 \mathrm{~mm} \mathrm{Hg}$ and energy density $\mathrm{Q}=8 \div 50 \mathrm{~J} / \mathrm{cm}^{2}$. Treatment was carried out once and multi time. The samples were placed at a distance of 6-10 $\mathrm{cm}$ from the end of the central electrode in a plasma focus area.

\section{Experiment}

In this paper, on the basics of $12 \mathrm{X} 18 \mathrm{~N} 10 \mathrm{~T}$ steel samples had studied the mechanism of growth of crystallites of the individual phases at the eutectic solidification of metallic alloys after exposure to plasma. The influence of the main parameters of the plasma treatment on the evolution of grain size, and as a result, the surface hardness of stainless steel. The images of treated samples surface was shown on figures 1-3. In the analysis of experimental data, we used the methods of X-ray diffraction (XRD) and scanning electron microscopy (SEM). Microhardness of the surface was determined by Vickers (HV) method on metallographic microscope "Metaval" under loading of indenter $20 \mathrm{~g}$.

Table 1. The results of X-ray analysis of stainless steel after treatment

\begin{tabular}{|c|c|c|c|c|c|c|c|}
\hline № обр. & $\mathbf{n}$ & $\mathbf{Q}, \mathbf{J} / \mathbf{c m} 2$ & $\mathrm{a}, \AA$ & 20max, grad. & Imax, abs. un. & phase & $\mathbf{L}, \AA$ \\
\hline \multirow[t]{2}{*}{ Исх. } & 0 & 0 & $3.5824 \pm 0.0006$ & 43.6892 .07018 & 902 & $\mathrm{Cr} 0,19 \mathrm{Fe} 0,7 \mathrm{Ni} 0,11$ & 1560 \\
\hline & & & - & 44.554 & 18.2 & $\mathrm{Fe} 5 \mathrm{C} 2$ & - \\
\hline \multicolumn{8}{|c|}{ One time impact } \\
\hline \multirow[t]{2}{*}{ №1 } & 1 & 8,5 & $3.5824 \pm 0.0006$ & 43.712 & 1490 & $\mathrm{Cr} 0,19 \mathrm{Fe} 0,7 \mathrm{Ni} 0,11$ & 470 \\
\hline & & & $2.8650 \pm 0.0007$ & 44.740 & 56.2 & $\mathrm{Fe}$ & 747 \\
\hline \multirow[t]{3}{*}{ №3 } & 1 & 19,95 & $3.5843 \pm 0.0006$ & 43.687 & 622 & $\mathrm{Cr} 0,19 \mathrm{Fe} 0,7 \mathrm{Ni} 0,11$ & 700 \\
\hline & & & $3.5901 \pm 0.0006$ & 43.540 & 253 & & \\
\hline & & & $2.8647 \pm 0.001$ & 44.702 & 27.9 & $\mathrm{Fe}$ & 1135 \\
\hline \multirow[t]{2}{*}{ №4 } & 1 & 27,1 & $3.5862 \pm 0.0006$ & 43.657 & 727 & $\mathrm{Cr} 0,19 \mathrm{Fe} 0,7 \mathrm{Ni} 0,11$ & 560 \\
\hline & & & $3.5949 \pm 0.0008$ & 50.737 & 63.3 & & \\
\hline №5 & 1 & 34,9 & $3.5868 \pm 0.0006$ & 43.659 & 751 & $\mathrm{Cr} 0,19 \mathrm{Fe} 0,7 \mathrm{Ni} 0,11$ & 530 \\
\hline №6 & 1 & 39,25 & $3.5866 \pm 0.0006$ & 43.649 & 815 & $\mathrm{Cr} 0,19 \mathrm{Fe} 0,7 \mathrm{Ni} 0,11$ & 470 \\
\hline \multicolumn{8}{|c|}{ Multi time } \\
\hline \multirow[t]{2}{*}{ №3 } & 10 & 27.2 & $3.5873 \pm 0.0006$ & 43.253 & 455.0 & Cr0.19Fe0.7Ni0.11 & 350 \\
\hline & & & $3.6113 \pm 0.004$ & & & FeN0.056 & 163 \\
\hline \multirow[t]{2}{*}{ №1 } & 20 & 23.1 & $3.5896 \pm 0.0015$ & 43.326 & 578.0 & $\mathrm{Cr} 0.19 \mathrm{Fe} 0.7 \mathrm{Ni} 0.11$ & 480 \\
\hline & & & $3.6104 \pm 0.0011$ & & & FeN0.056 & 123 \\
\hline \multirow[t]{2}{*}{ №2 } & 30 & 30.1 & $3.5892 \pm 0.0006$ & 43.325 & 410.0 & $\mathrm{Cr} 0.19 \mathrm{Fe} 0.7 \mathrm{Ni} 0.11$ & 440 \\
\hline & & & $3.6162 \pm 0.0026$ & & & FeN0.056 & 133 \\
\hline
\end{tabular}

Scherer's method used in the XRD to determine the crystallite size of main phases, it was found that the single effect of the plasma density variation energy $\mathrm{Q}$ in a given interval $(\mathrm{P}=0.04 \mathrm{mmHg})$ reduces the size of the main phase of the crystallites were $\gamma-\mathrm{Fe} \sim 2$ time (Table 1). The greatest effect is achieved by grinding grain $\mathrm{Q}=8,5 \mathrm{~J} / \mathrm{cm}^{2}$. The increase of Q causes small fluctuations is shown, while the crystallization process is not stable, then the phase Fe $\gamma$ grain size does not change. Such changes in the surface structure can be explained by the conditions of the process, in particular the selected operating pressure at which the CPU-30 to reach a maximum value of the energy density of the plasma flow. The degree of melting in this case may lead to unexpected side effects. For example, the presence of a small amount of ferrite phase in the sample number 1 , 3 , the amount of which decrease and disappear at the sample number 4 .

In addition, the sample number 3,4 , revealed the presence of two phases with the structure $\gamma$-Fe (austenite) to the parameters of a FCC lattice, close to the parameters 
of the main phase $\mathrm{Cr}_{0,19} \mathrm{Fe}_{0,7}, \mathrm{Ni}_{0,11}$, but differ greatly. The content of the second phase of austenite is approximately one-third of the content of the main phase of $\gamma$-Fe. Perhaps this refers to the austenite phase, which is not on the surface, but in the depth of the sample. With Q

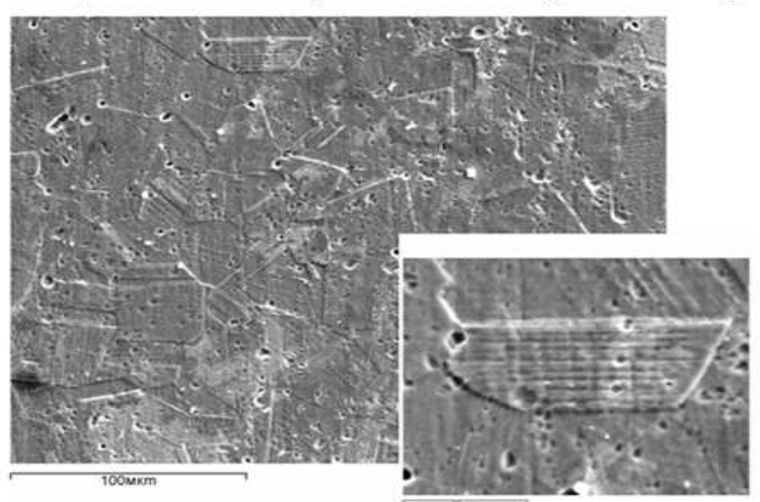

increasing the second phase of the austenite structure disappears (sample number 5,6 ), possibly due to the fact that the process of modifying the sample affects the deeper layers of the sample.

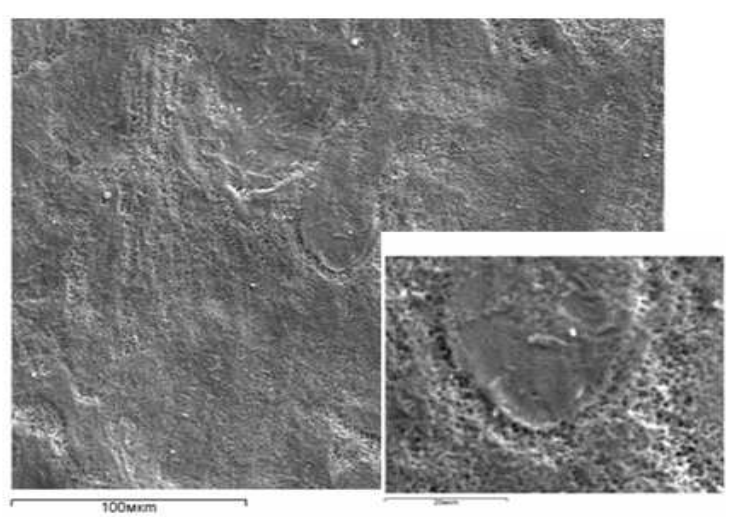

Figure 1. Topography of the sample number $1\left(Q=8,5 \mathrm{~J} / \mathrm{cm}^{2}, n=1\right)$, № $4\left(Q=27,1 \mathrm{~J} / \mathrm{cm}^{2}, n=1\right)$ general view $(\times 400)$ and a fragment $(\times 2000)$ after treatment with $P=0.04 \mathrm{~mm} \mathrm{Hg}$ respectively
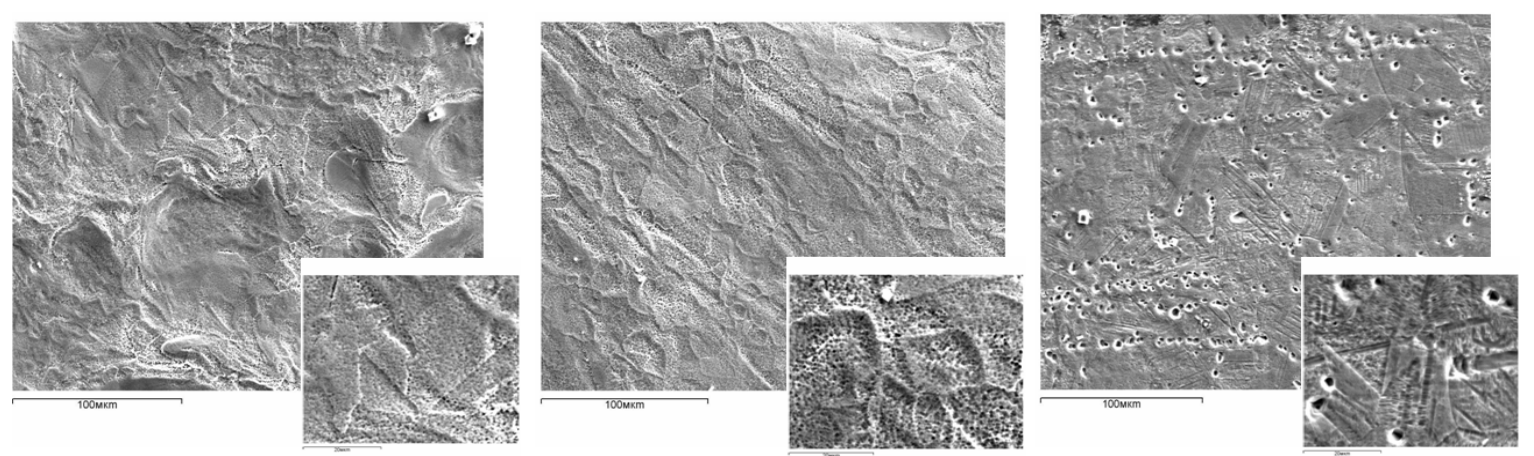

Figure 2. The surface of the samples № $1\left(Q=4,2 \mathrm{~J} / \mathrm{cm}^{2}, n=1\right)$, № $3\left(Q=8 \mathrm{~J} / \mathrm{cm}^{2}, n=1\right)$ and № $4\left(Q=22,8 \mathrm{~J} / \mathrm{cm}^{2}, n=1\right)$ general view $(\times 400)$ and a fragment $(\times 2000)$ after treatment at $P=0.1 \mathrm{~mm} \mathrm{Hg}$
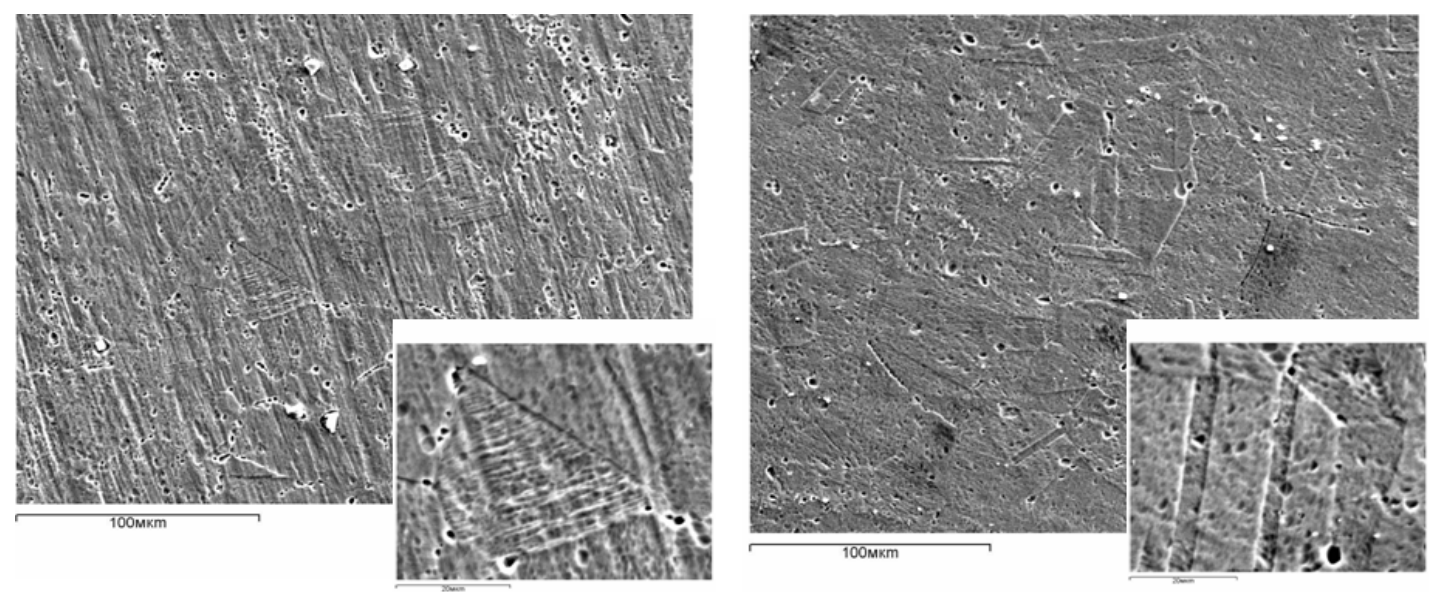

Figure 3. The surface of the sample number $2\left(Q=10,35 \mathrm{~J} / \mathrm{cm}^{2}, n=1\right)$, № $3\left(Q=19,9 \mathrm{~J} / \mathrm{cm}^{2}, n=1\right)$ general view $(\times 400)$ and a fragment $(\times 2000)$ after treatment with $P=0.5 \mathrm{~mm} \mathrm{Hg}$ respectively

With increasing numbers of treatment (up to 10,20 and 30 time) the structure of the sample surface stainless steel 12X18N10T modified in solid solution in which the main are two phases: the austenite $-\mathrm{Cr}_{0.19} \mathrm{Fe}_{0.7} \mathrm{Ni}_{0.11}$ and iron nitride. The elemental composition of iron nitride is expressed by $\mathrm{FeN}_{0.056}$. Small crystallite size may be due to a reduced of crystalline degree of nitride. A small number of samples in the presence of a third phase, which can be identified as $\mathrm{Fe}_{3} \mathrm{C}$ - iron carbide.

Effect of plasma treatment parameters $\mathrm{Q}$ and $\mathrm{P}$ on the 
crystallite structure apparent when studying the surface of steel $12 \mathrm{X} 18 \mathrm{~N} 10 \mathrm{~T}$ by SEM (Figure 1, 2, 3). To identify the microstructure was chosen mode of electrolytic etching plasma-treated samples for grain.

On the pictures is clearly visible a transformation of grain with increasing of $\mathrm{Q}$ and $\mathrm{P}$. The presence of various rack-and-plate-crystalline structure with a distinct defect of twinning on many samples, suggesting the presence of a phase transition of $\gamma$-Fe lattice in the $\alpha$-Fe (martensite phase) with another type of lattice. Since in this case the martensite phase to the austenite is more stable, such a transition should be accompanied by a hardening of the material surface. Fluctuations in grain size, marked XRD associated with the phase transformation, the formation of a well-known compounds and the new, the occurrence of which is not predicted by the equilibrium phase diagram.

Table 2. Stoichiometric changes in steel 12 X18N10T after processing

\begin{tabular}{|c|c|c|c|c|c|c|c|c|}
\hline № sumple & Al, $\%$ & $\mathrm{Si}, \%$ & $\mathbf{T i}, \%$ & $\mathrm{Cr}, \%$ & Mn, \% & Fe, $\%$ & $\mathrm{Cu}, \%$ & $\mathrm{Ni}, \%$ \\
\hline 4 (initial) & - & 0,68 & 0,21 & 17,85 & 1,58 & 70,61 & - & 9,07 \\
\hline \multicolumn{9}{|c|}{ At air work pressure $0,1 \mathrm{~mm} \mathrm{Hg}$. } \\
\hline 4 (one time) & - & 0,67 & 0,16 & 17,96 & 1,69 & 70,42 & 0,39 & 9,10 \\
\hline 3 (10 time) & - & 0,67 & 0,33 & 17,81 & 1,40 & 70,61 & 0,33 & 8,85 \\
\hline $1(20-)$ & - & 0,63 & 0,26 & 17,87 & 1,62 & 70,32 & - & 9,30 \\
\hline $2(30-)$ & - & 0,69 & 0,24 & 17,83 & 1,74 & 69,78 & 0,51 & 9,21 \\
\hline \multicolumn{9}{|c|}{ At $\mathrm{P}=0,5 \mathrm{~mm} \mathrm{Hg}$. } \\
\hline 3 (one time) & 0,10 & 0,86 & 0,20 & 17,69 & 1,62 & 70,31 & - & 9,23 \\
\hline 5 (multi time) & - & 0,71 & 0,21 & 17,82 & 1,57 & 70,31 & 0,39 & 8,98 \\
\hline
\end{tabular}

As we know, the birth of new compounds proceeds in parallel processes of defect, the result of which is the appearance of micro-inclusions, areas of damage and plastic deformation characteristic of doping impurities and chemically active, directly or indirectly, by affecting the synthesis of new phases and the restructuring of the treated surface. When the concentration of implanted ions stoichiometric values in the matrix formation of compounds that require minimal restructuring. Table. 2 shows the changes in the elemental composition of the samples were $12 \mathrm{X} 18 \mathrm{~N} 10 \mathrm{~T}$ when processed in the given conditions. After processing we can see the changes of surface microhardness of treated samples, as shown in works [7]. Single exposure leads to an increase of microhardness to 1.5 - 2 times as a result of treatment at a pressure of $0.5 \mathrm{~mm} \mathrm{Hg}$, repeated - almost three times at = $0.1 \mathrm{~mm} \mathrm{Hg}$.

\section{Conclusion}

For common (carbon) steel samples the single time treatment by plasma flow is enough for significant modification of properties [8]. The studies have shown that for stainless steel samples repeated treatment is more effective. It is shown that the dependence of $\mathrm{HV}$ on the multiplicity of effects is almost linear. One of the reasons for the increase in microhardness, apparently, are the structural changes, including the formation of hardening nitride and carbide phases. As known, when implanted iron-based alloys with nitrogen ions increase the radiation dose to $4 \cdot 10^{16} \mathrm{~cm}^{-2}$ at room temperature leads to the appearance of the martensite phase, which when heated to temperatures of $426 \mathrm{~K}$ into a tetragonal $\mathrm{BCC}$ grid iron nitride [8]. And as in the experiment, surface treatment of steel $12 \mathrm{X} 18 \mathrm{~N} 10 \mathrm{~T}$ done repeatedly, as the plasma gas was used by the air that N2 is one of the main components, and the results of X-ray analysis showed the presence of nitride phase, we can assume that these conditions impulse excitation can initiate similar phase transformation. Strengthening also helps reduce the size of the crystallites with repeated exposure.

\section{References}

[1] V. V. Chebotarev, I.E. Garkusha, A.M. Bovda, V.I. Tereshin, "Application of pulsed plasma accelerators for surface modification", Nukleonika, 2001. N.46, p.27-30;

[2] J. Langner, J. Piekoszewski, J. Stanisiawski, Z. Werner, "Present status and prospects of research in SINS on the modification of surface properties by pulsed plasma streams," Nukleonika, Vol. 45, No. 3, 2000, pp.193-197.

[3] V.M. Anishik, V.V. Uglov. Modification of instrumental materials by ion and plasma beams. Minsk.: BGU, 2003, 191 p.;

[4] F. B Baimbetov, A. M. Zhukeshov, A. U. Amrenova, "Dynamics of plasma flow formation in a pulsed accelerator operating at a constant pressure", Technical Physics Letters, Vol. 33, 2007, pp. 77-79.

[5] A. M. Zhukeshov, "Plasma flow formation in a pulse plasma accelerator in continuous filling regime", Plasma Deices and Operations, Vol. 17, 2009, pp. 73-81.

[6] A. Zhukeshov. "Plasma diagnostics in a pulsed accelerator used for material processing", Journal of Physics. Conference series, Vol.63, No 012014, 2007.

[7] A.M. Zhukeshov, A.T. Gabdullina, "Vlianie rejimov obrabotki impulsnymi potokami plasmy na poverchnost stali io structuru i microtverdost // Poverhnost, №11, 2009, pp. 95-101.

[8] A. M. Zhukeshov, A.T. Gabdullina, A.U. Amrenova, S. P. Pak "Structure and microhardness of steel sumples after pulse plasma flows processing," Mat. Sci. Applications.., in press. 
[9] I.A. Abroyan , A.N. Andronov., A.I. Titov "Fizicheskie osnovy electronnoy ionnoy technologii", M. : High School, 1984, $320 \mathrm{p}$. 